\title{
APPRAISAL OF NONLINEAR DYNAMIC SOIL- STRUCTURE INTERACTION MODEL FOR PILE FOUNDATION SUPPORTED STRUCTURE: A PROBABILISTIC APPROACH
}

\author{
Rajib Saha ${ }^{1}$ and Abhinava $\mathrm{Pal}^{2}$
}

\begin{abstract}
Beams on non-linear Winkler foundation (BNWF) modelling is a well-acceptedapproach for modelling dynamic soil structural interaction in pile foundation supported structure under seismic loading. This modelling approach is developed considering soil parameters as deterministic quantity. However, in reality, the natural soil properties vary considerably within geologically distinct layers, which may affect the dynamic behavior of the system. Hence, probabilistic model for the assessment of design response of pile foundation supported structures considering SSI is necessary. Present study examines the effect of variability in shear strength of soil and strain parameters considering BNWF modeling approach. The soil resistance is modeled using American Petroleum Institute prescribed non-linear $p$-y curves for BNWF model. Dynamic analysis of soil-piled foundationsuperstructure is carried out in time domain when subjected to seismic loading and incorporating variability in soil shear strength and strain parameters. Response statistics of the system are estimated using Monte Carlo analysis. Finally, design implications are suggested for seismic design of pile foundation supported structure with an emphasis on probabilistic SSI modeling approach.
\end{abstract}

Keywords - Dynamic analysis, Soil-structure interaction, BNWF, Impedance approach, Reliability

\section{INTRODUCTION}

Seismic design of structures supported on pile foundation is bit challenging and complex as the mechanism of transfer of lateral loads to soil mass is dependent on the attributes of sub-soil and pileimpedance contrast. The failure of structures due to inadequacy of foundation design leads to loss of life and property. Thus, precise estimation of safety margin is required for sustainable design of such structure under uncertain loads like seismic events with an acceptable risk. Importance of dynamic soil structure interaction (DSSI) has been evidenced from post-failure analysis of pile supported structures during past earthquakes and could be a sustainable seismic design solution. Conventional design considers fixed base design approach without taking into account of uncertainty of soil parameters. However, the behavior of soil is complex and it may invite various uncertainties which influences the dynamic response of structure. Primary sources of soil uncertainties are inherent variability, measurement error, and transformation uncertainty (Phoon and Kulhway 1999). The inherent uncertainty is beyond engineer's control, while others can be minimized with better quality control and sophisticated model for analysis. Hence, probabilistic design is necessary to predict the safety margin for pile foundation rationally. Previous studies have addressed probabilistic seismic design of pile with an emphasis on different reliability based approaches (e.g. Tandjiria et al. 2000, Haldar and Babu 2008, Pula and Rozanski 2012).

In this study the inherent variability of soil undrained shear strength of clay $\left(C_{u}\right)$, bearing capacity factor $(J)$ and strain parameter $\left(\varepsilon_{50}\right)$ on the seismic response of structures supported by piled-raft foundation is examined. Probabilistic analysis of seismic response of soil-piled raft-structure is carried out considering SSI incorporating inherent variability of soil parameters. Beam on nonlinear Winkler foundation approach is adopted to model the soilpile raft-structure interaction. The soil resistance is modeled using non-linear $p-y, t-z$ and $q-z$ springs. The undrained shear strength $\left(C_{u}\right)$ of soil are considered as random variable. The spatial variability of $C_{u}$ is modeled considering nonGaussian random field, which is described by the mean, coefficient of variation (COV) and scale of fluctuation and

${ }^{1}$ Civil Engineering Department National Institute of Technology Agartala, Agartala, Tripura, India

${ }^{2}$ Civil Engineering Department National Institute of Technology Agartala, Agartala, Tripura, India 
considered to be followed log-normal probability density function. Further, bearing capacity factor $(J)$ and strain parameter $\left(\varepsilon_{50}\right)$ are idealized as random variable parmeter. Monte Carlo simulation (MCS) is used to generate 1000 number of sample realizations of the selected random variables. This study shows that soil non-linearity and uncertainty greatly affects the system responses and suggests modification of conventional seismic design for sustainable design.

\section{II.SYSTEM MODELING}

\section{$2.1 \quad$ Soil-piled raft-structure modelling -}

Superstructure is idealized as a lumped mass stick model structure having single degree of freedom. Column is modeled using an inelastic beam-column element. Response of the superstructure is obtained for considering fixed base and SSI condition. Raft is modeled as four noded shell element, having six degrees of freedom at each node. Plan dimension of raft is considered as $10 \mathrm{~m} \times 10 \mathrm{~m}$ which is discretized into $0.5 \mathrm{~m} \times 0.5 \mathrm{~m}$ small elements based on a convergence study. A moderately rigid raft is selected in this study considering the relative stiffness of raft and soil $\left(k_{r s}\right)$ as suggested by Horikoshi and Randolph (1998),

$$
k_{r s}=4 E_{r} B_{r} t_{r}^{3}\left(1-v^{2}\right) / 3 \pi E_{s} L_{r}^{4}\left(1-v_{r}^{2}\right)
$$

where $E_{r}$ and $E_{s}=$ Young's modulus of raft and soil respectively, $L_{r}$ and $B_{r}=$ raft length and breadth respectively, $t_{r}=$ raft thickness, $v$ and $v_{r}=$ Poisson's ratio of soil and raft respectively. The value of $k_{r s}=1$ denotes a moderately rigid raft, hence used for analysis.

Pile is modelled by a displacement based elastic beam-column element having 6 degrees of freedom at each node and total length is meshed into $0.9 \mathrm{~m}$ interval after a convergence study. Pile head is attached with the raft node by a rigid link to follow the same degrees of freedom of raft element. Beam on nonlinear Winkler foundation (BWF) model is used to model the raft-soil and pile-soil interaction. Soil beneath the raft is idealized as distributed springs connected to each node of the raft in all translational degrees of freedom. The stiffness values of non-linear idealizations of these of the soil springs is estimated based on the literature (Matlock (1970) (cf. Table 1). Nonlinear pile-soil interaction is modeled used following the Boulanger et al. (1999) and Curras et al. (2001), summarized in Table 1. Note that, frequency dependent soil springs are not used in this study, as the selection of a particular frequency value is unrealistic for seismic motion (Parmelee et al. 1968). Soil damping is idealized as linear dashpots which are connected as parallel to the soil springs for raft and pile. Figure 1 shows the finite element model for soil-piled raft-structure system. This study considers 5\% of critical damping in each mode regardless of structural support condition. Roy and Dutta (2010) showed that consideration of higher damping for soil (including material and radiation) even up to $30 \%$ of critical damping makes marginal difference in maximum response of the system than that of case of 5\% damping of soil-foundation and super-structure. Therefore, to strike a balance between rigour and accuracy, $5 \%$ of critical damping in each mode of vibration of pile-raft-soil and superstructure system is considered for the present study regardless of structural support condition. Sinusoidal acceleration with a frequency equal to the fundamental frequency of the system having an amplitude of $0.02 \mathrm{~g}-0.05 \mathrm{~g}$ are applied at the base of structure. Dynamic analysis is carried out in an open source program OpenSees (Mazzoni et al. 2007).

Table 1- Summary of raft-soil and pile-soil interaction modelling

\begin{tabular}{|c|c|}
\hline Interaction & Non-linear idealization \\
\hline $\begin{array}{l}\text { Raft-soil } \\
\text { interaction }\end{array}$ & $\begin{array}{l}\text { Lateral and vertical soil resistance is modelled as } p-y \text { and } q-z \text { spring respectively (Matlock 1970): } \\
p=0.5 p_{u l t}\left(y / y_{c}\right)^{1 / 3} \text { for } y<y_{c} \text {, and } p=p_{\text {ult }} \text { for } y \geq y_{c} \text {. Ultimate lateral soil resistance, } p_{u l t}= \\
N_{p} C_{u} B \text {, end bearing resistance, } q_{u l t}=5.4 C_{u} \Delta z \text {, where } \Delta z=\text { size of mesh, } N_{p}=\text { bearing capacity } \\
\text { factor, } B=\text { width of raft. } y_{c}=\text { critical raft deflection }=2.5 \varepsilon_{50} B, \varepsilon_{50}=\text { strain corresponding to a } \\
50 \% \text { ultimate stress from a laboratory stress-strain curve. }\end{array}$ \\
\hline $\begin{array}{l}\text { Pile-soil } \\
\text { interaction }\end{array}$ & $\begin{array}{l}\text { Dynamic } p-y, t-\mathrm{z} \text { and } q \text {-z springs as suggested by Boulanger } \text { et al. }(1999) \text { and Curras } e t \text { al. (2001) } \\
\text { based on benchmark stiffness curve proposed by Matlock }(1970) \text { as presented above. The input } \\
\text { parameters are given below. } p_{u l t}=N_{p} C_{u} d, N_{p}=\left(3+\gamma z / C_{u}+J z / d\right) \leq 9, y_{c}=2.5 d \varepsilon_{50} \text {, where } d= \\
\text { pile diameter, } \gamma=\text { average buoyant unit weight, } \mathrm{z}=\text { depth below ground level, } J=0.5 \text {. Group } \\
\text { interaction factor }=0.7 \text { (Brown } \text { et al. } 1987) \text {. Drag resistance } C_{d}=c_{d} p_{u l t} \text {; where } c_{d}=\text { ratio of the } \\
\text { maximum drag force to the ultimate resistance of the } p-y \text { material }(=1.0 \text { in this study). }\end{array}$ \\
\hline
\end{tabular}




\subsection{Modeling of soil uncertainity and probabilistic analysis -}

Properties of soil vary from point to point maintaining a correlation to each other. This is termed as spatial variability in theory of probability. The spatial variability deals with random field theory. In this study, undrained soil shear strength $\left(C_{u}\right)$ is modelled by random field. The random field is generated following Haldar and Babu (2008) within the finite element grids by assigning $C_{u}$ at each grid location which is not presented herein due to brevity. Soil undrained shear strength $\left(C_{u}\right)$ is considered as log-normally distributed random variable represented by parameters mean $\mu_{C u}$, standard deviation $\sigma_{C u}$ and spatial correlation distance $\delta_{z}$. In addition two other parameters used in defining non-linear, pile-soil lateral load deformation behaviour, such as load resistance factor $J$ and strain parameter $\left(\varepsilon_{50}\right)$ corresponding to $50 \%$ of ultimate stress are modeled as random variables with a known COV value obtained from load test data.

Deterministic soil parameters presented in Table 2 are assumed as mean values for probabilistic analysis. However, the present study is limited to very soft clay considering the fact that pile foundation is mostly used in soft deposit. Figure 2 (a) and (b) presents the discretization of finite element grid for pile and raft element supported by nonlinear Winkler springs for the sake of understanding of evaluation of correlation matrix. The probability analysis is conducted for a range of variability and a correlation parameter of soil. The range of values is selected based on the typical range for coefficient of variation $\left(\mathrm{COV}_{C u}\right)$ of shear strength (10\%-50\%) as suggested by Phoon and Kulhway (1999). Further, the COV of $J$ and $\varepsilon_{50}$ is considered as $38 \%$ and $68 \%$ as obtained from ensemble of load test data.The parameters utilised for the probabilistic study are presented in Table 2 below.

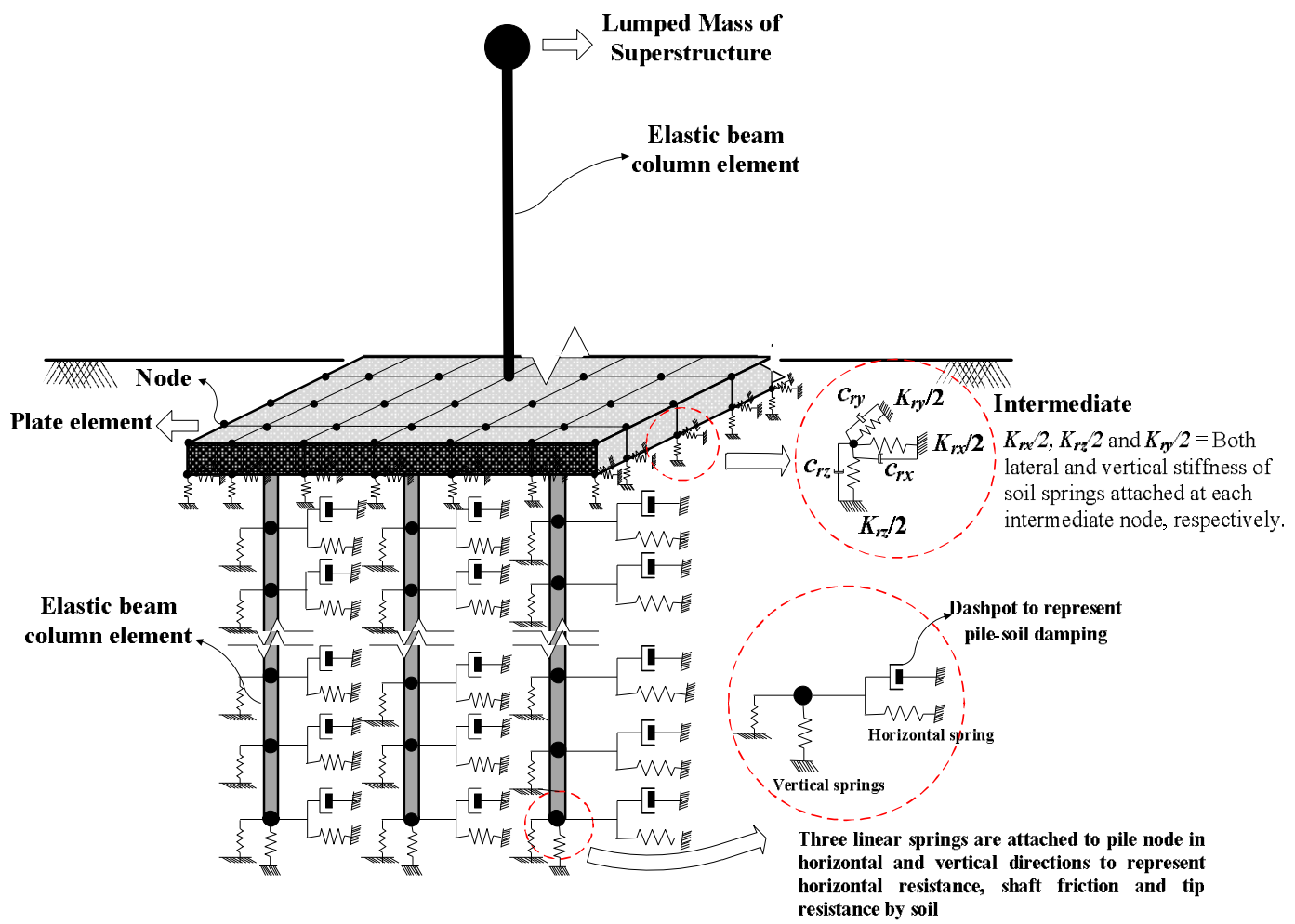

Figure 1. Idealization of soil-pile raft-structure modeling.

Monte Carlo simulation (MCS) is adopted in present study for probabilistic analysis to generate non-linear pile-soil and raft-soil realisation in three orthogonal directions ( $p-y, t-z, q-z$ springs) based on randomly generated sampling sets of in-situ design soil parameters. The spatially distributed $C_{u} J$ and $\varepsilon_{50}$ is introduced as input to non-linear dynamic pile-soil stiffness for the sake of generation of set of dynamic $p-y, t-z$ and $q-z$ non-linear curves for raft and pile elements. For each $p-y, t-z$ and $q-z$ non-linear dynamic stiffness curve, the dynamic characteristics and response of the system under sinusoidal loading is calculated. The range of coefficient of variation $\left(\mathrm{COV}_{C u} \%\right)$, correlation 
Appraisal Of Nonlinear Dynamic Soil-Structure Interaction Model For Pile Foundation Supported Structure: A

distance $\left(\delta_{z}\right)$ are considered as 10, 30, 50 and 1.5, 5.0 m respectively in present study. Based on a convergence study, the number of sample realizations for MCS analysis is considered as 1000 .

Table 2- Pile and Soil data used for deterministic analysis

\begin{tabular}{ll}
\hline Pile data & Value \\
\hline Pile diameter, $d(\mathrm{~m})$ & 0.3 \\
Pile length, $L(\mathrm{~m})$ & 18 \\
Young's modulus of pile, $E_{p}\left(\mathrm{kN} / \mathrm{m}^{2}\right)$ & $21.78 \times 10^{6}$ \\
Poisson's ratio of concrete & 0.17 \\
Section modulus, $Z\left(\mathrm{~m}^{3}\right)$ & 0.0045 \\
Flexural strength of pile, $F_{y}\left(\mathrm{kN} / \mathrm{m}^{2}\right)$ & 3050 \\
Flexural moment of pile section, $M_{y}(\mathrm{kN} \mathrm{m})$ & 13.725 \\
\hline Soil data & \\
\hline Soil consistency & Very soft \\
Undrained cohesion, $c_{u}\left(\mathrm{kN} / \mathrm{m}^{2}\right)$ & 9.80 \\
$S P T N$ value & 1 \\
$\gamma_{\text {sat }}\left(\mathrm{kN} / \mathrm{m}^{3}\right)$ & 13.50 \\
Young's modulus, $E_{s}\left(\mathrm{kN} / \mathrm{m}^{2}\right)$ & 2500 \\
Poisson's ratio & 0.4 \\
\hline
\end{tabular}
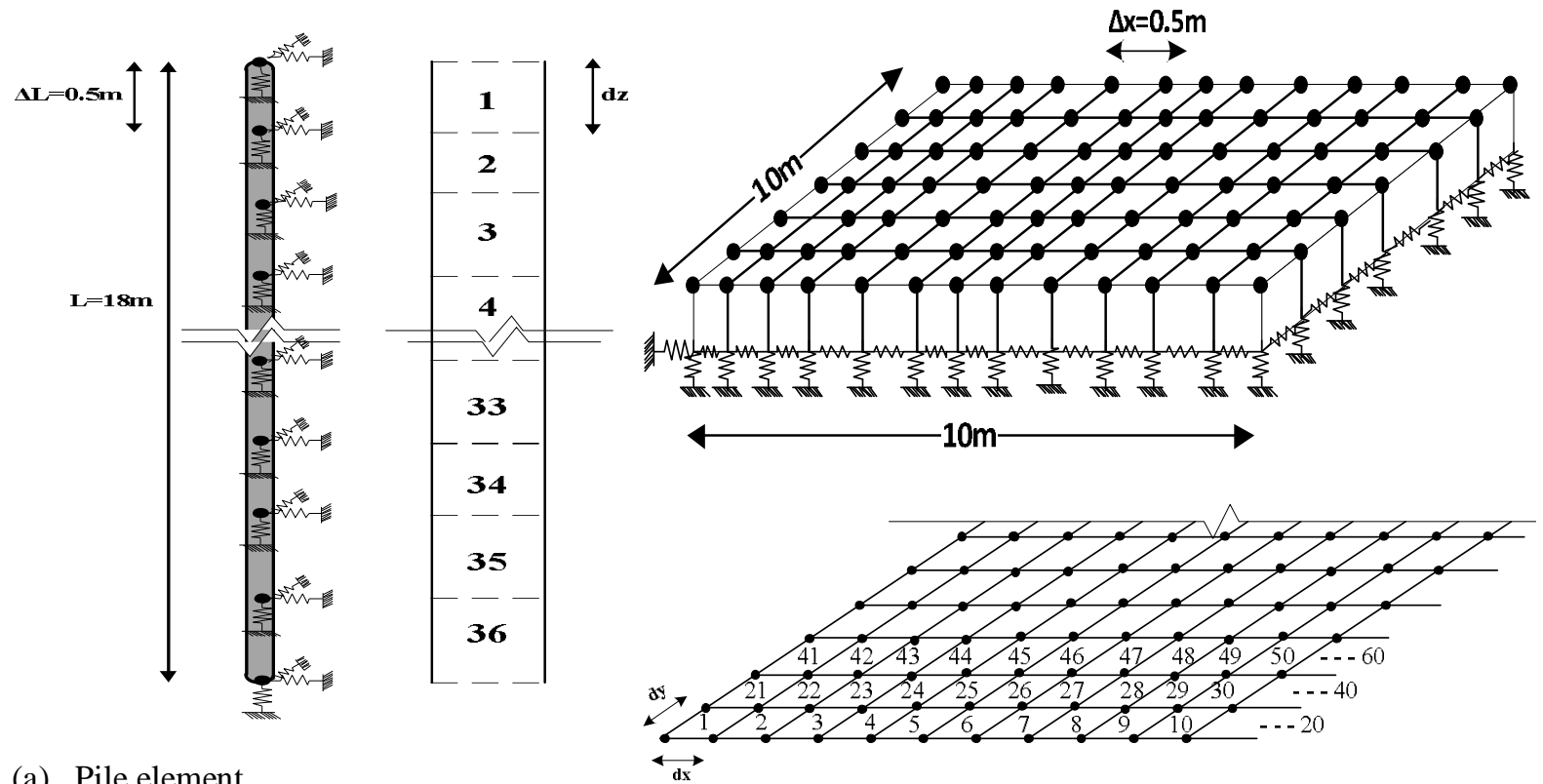

(a) Pile element

(b) Raft element

Figure 2. Discretization of finite element grid to generate spatial variability of soil

\subsection{Parametric studies -}


A parametric study considering a period of structure at fixed base condition $\left(T_{\text {fixed }}\right)$, such as, $T_{\text {fixed }}=2.0 \mathrm{sec}$ supported by $9 \times 9$ pile group embedded in very soft consistencies of homogenous clay deposit with uniform variation of $E_{s}$ is attempted in present study. A representative structures with $T_{\text {fixed }}=2.0 \mathrm{sec}$ (18 storey) is taken in order to represent the short period structure. Pile groups are designed for gravity loading based on spacing $(S)$ to diameter $(d)$ ratio $(S / d)$ of 3 and length $(L)$ to diameter $(d)$ ratio of 60 . Note that, this study is limited to a high $L / d$ ratio.

\section{RESULTS AND DISCUSSION}

\subsection{Method of Analysis and Evaluation of Sample Size for MCS-}

Time history analysis is performed to obtain the dynamic response of the finite element model of soil-piled raftstructure system. Newmark's $\beta-\gamma$ method ( $\beta=0.5, \gamma=0.25$ ) considering a small time step of $T / 100$ is used to solve the dynamic motion of equation, where $T$ is the fundamental time period of the structure. Both deterministic analysis based on single value deterministic parameters (considered as mean parameters as given in Table 2) and probabilistic analysis is performed in present study considering soil modelled nonlinear material.

\subsection{Influence of Variability on p-y Behavior-}

Primarily, the effect of spatially distributed undrained shear strength of soil $\left(C_{u}\right)$ and random variable parameters, such as, $J$ and $\varepsilon_{50}$ are studied on lateral load deformation $(p-y)$ behaviour of pile soil system under dynamic loading. Fig. 3(a) and (b) presents the mean normalized load $\left(p / p_{u l t}\right)$ with respect to deformation $\left(y / y_{c}\right)$ at central node of pile head under steady state loading considering $\mathrm{COV}_{C u}=10 \%$ and $50 \%$ respectively. Fig. 3(a) indicates an insignificant variation in normalised load and deformation at pile for deterministic and probabilistic cases pertaining to $\mathrm{COV}=10 \%$. While, for $\mathrm{COV}=50 \%$, the variation is found to be significant which may influence the dynamic response of the system considerably. The effect of random variable $J$ and $\varepsilon_{50}$ on lateral load deformation (p-y) behaviour of pile soil system under dynamic loading are presented Figure 4 and 5 respectively. A significant variation in dynamic $p-y$ curve is observed due to consideration of variability in bearing capacity factor $J$ irrespective of $E_{p} / E_{s}$ variation. It is observed from Figure 4(a) that probabilistic normalised $p$-ycurve exhibits reduction in pile-soil nonlinear stiffness as compared to deterministic counterpart. On the other hand, Figure4(b) shows that probabilistic pile stiffness increases with corresponding increase in lateral soil reaction as compared to deterministic pile stiffness. Hence, it may be inferred that effect of in-situ variability of $J$ parameter has a considerable effect on dynamic $p$-ybehaviour of pile soil and may lead to overestimation and underestimation of pile response in soft and stiff soil respectively due to deterministic SSI analysis. Figure 5 indicates that the variability effect of $\varepsilon_{50}$ is marginal in nonlinear lateral load deformation $(p-y)$ behaviour of pile soil system under dynamic loading irrespective of change in $E_{p} / E_{s}$.
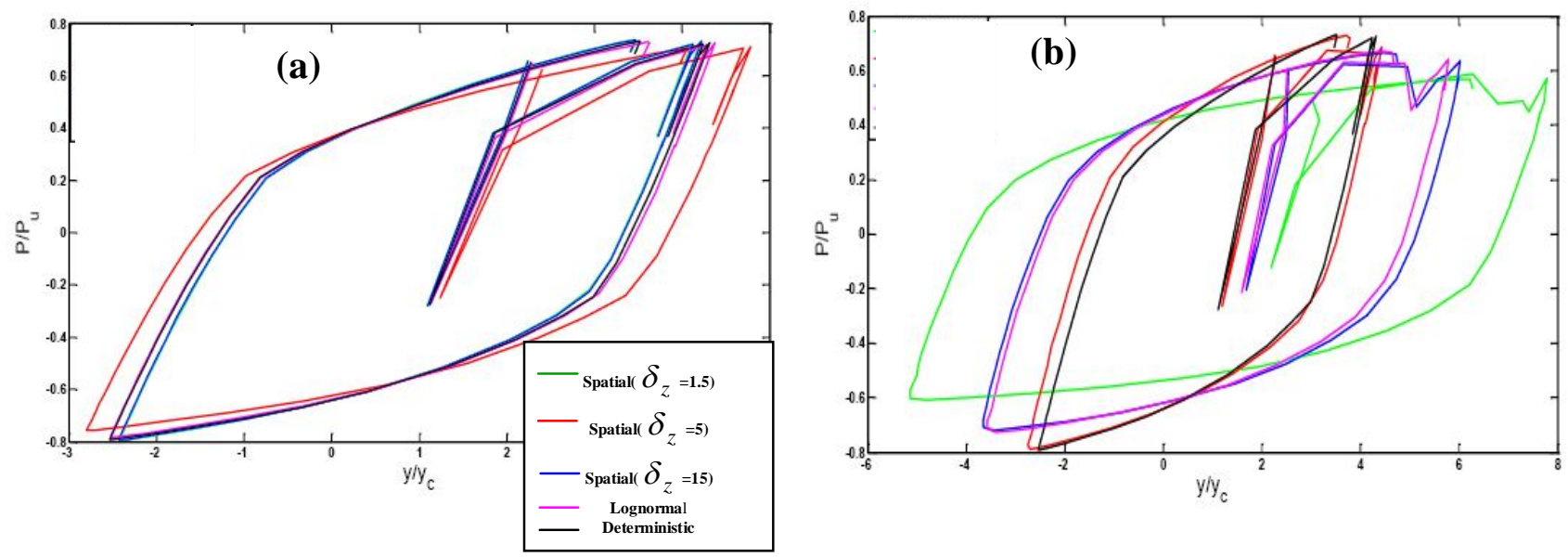

Figure 3. Normalized $p-y$ curves at pile head of $9 \times 9$ pile group having $E_{p} / E_{s}=10000$ supporting structure of $T_{\text {fixed }}$ $=2.0 \mathrm{sec}$ for (a) $\mathrm{COV}_{C u}=10 \%$ and (b) $\mathrm{COV}_{C u}=50 \%$ under dynamic loading 

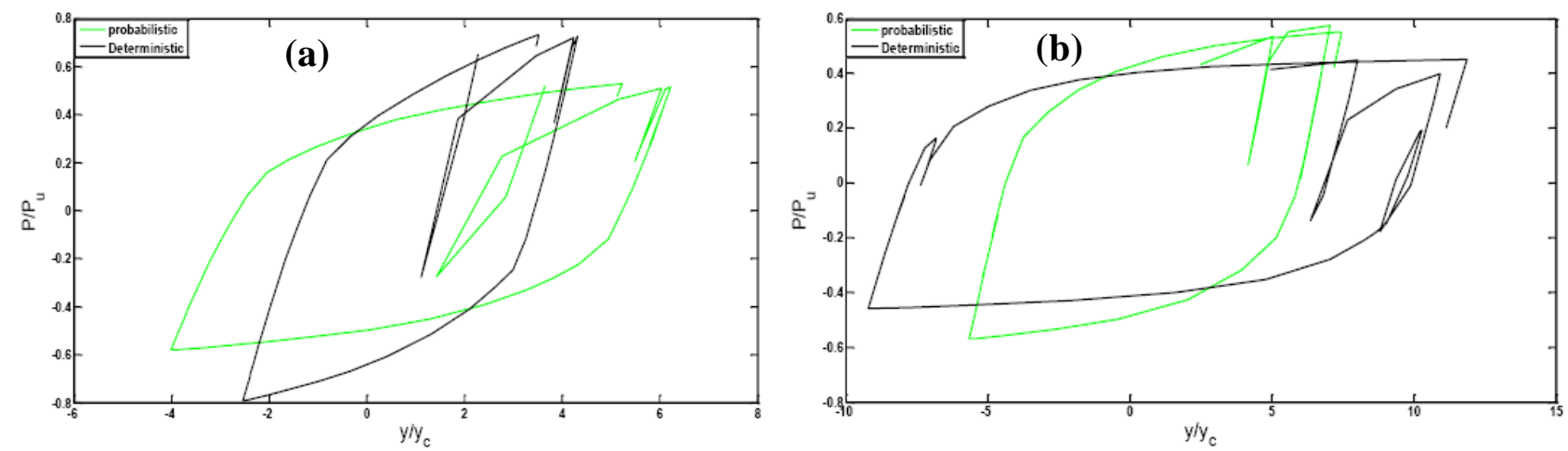

Figure 4. Normalized $p-y$ curves at pile head of $9 \times 9$ pile group having $\operatorname{COV} J=38 \%$ supporting structure of $T_{\text {fixed }}=2.0$ sec for (a) $E_{p} / E_{s}=10000$ and (b) $E_{p} / E_{s}=1500$ under dynamic loading
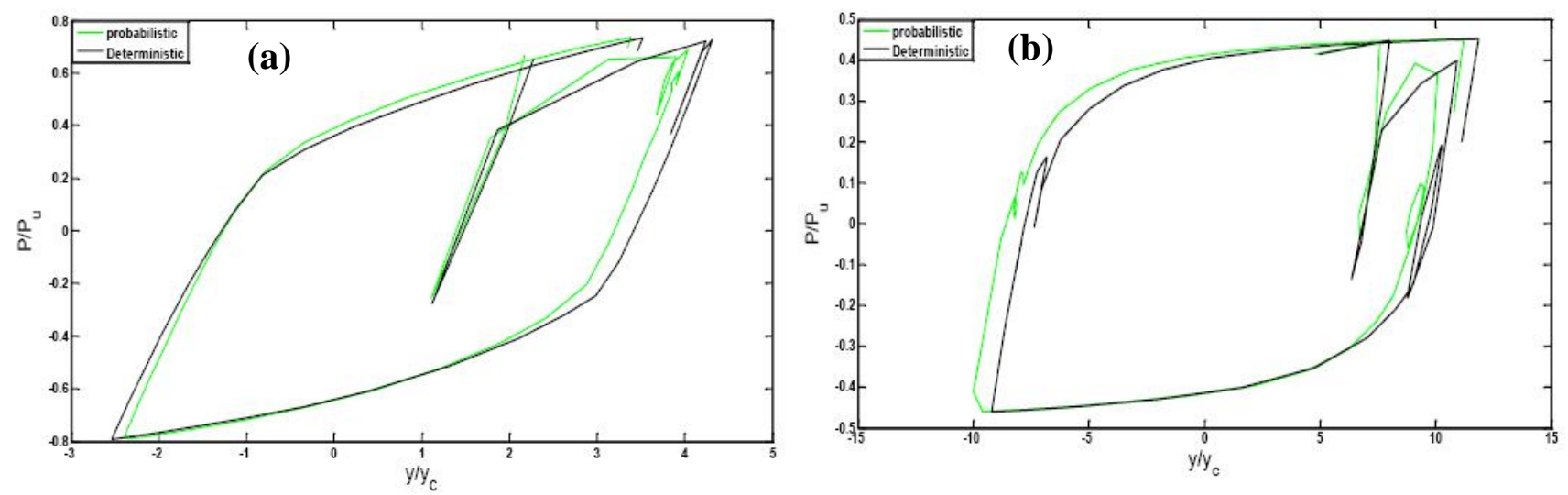

Figure 5. Normalized $p-y$ curves at pile head of $9 \times 9$ pile group having $\operatorname{COV} \varepsilon_{50}=68 \%$ supporting structure of $T_{\text {fixed }}$ $=2.0 \mathrm{sec}$ for (a) $E_{p} / E_{s}=10000$ and (b) $E_{p} / E_{s}=1500$ under dynamic loading

\section{IV.CONCLUSION}

The present study is attempted to assess the effect of in-situ variability of soil strength and strain parameters on dynamic response of soil-piled raft-structure system considering soil as non-linear viscous material. The influence of spatial variability of undrained shear strength $\left(C_{u}\right)$ is found to be marginal in dynamic response of pile foundationsoil system for $\mathrm{COV}_{C u}=10 \%$ if soil is modelled as nonlinear $p-y$ curve suggested by Matlock (1970). However, variability of undrained shear strength $\left(C_{u}\right)$ have significant effect on response parameters when $\operatorname{COV}_{C u}=$ $50 \%$.Further, the variability in bearing capacity factor $J$ has significant effect on dynamic response of soil-pile foundation system, while, the effect is further varied with $E_{p} / E_{s}$ variation. The influence of soil strain parameter $\varepsilon_{50}$ on dynamic response of foundation is marginal. Hence, the present study indicates the importance of consideration of SSI along with in-situ variability of soil design parameters in order to obtain reasonably accurate response of a structural system which may give a sustainable design solution of such heavy structural system.

\section{REFERENCES}

[1] Phoon, K.K. and Kulhawy, F.H. (1999). "Characterization of geotechnical variability," Canadian Geotechnical J., Vol.36: 210-38.

[2] Tandjiria,V., Teh, C.I. and Low, B.K. (2000). "Reliability analysis of laterally loaded piles using response surface methods," Structural Safety, Vol.22: 335-355.

[3] Pula, W. and Rozanski, A. (2012). "Reliability of rigid piles subjected to lateral loads," Structural Safety, Vol.12: 205-218.

[4] Haldar, S. and Babu, G.L. S. (2008). "Effect of soil spatial variability on the response of laterally loaded pile in undrained clay," Computers and Geotechnics, Vol.35: 537-547.

[5] American Petroleum Institute. (2005). "Recommended Practice for Planning, Designing and Constructing Fixed Offshore PlatformsWorking Stress Design”, pp-75-81. 
[6] Matlock, H. (1970). "Correlations for Design of Laterally Loaded Piles in Soft Clay," In: Proc., $2^{\text {nd }}$ Annual Offshore Technology Conference, 1: 577-594.

[7] Parmelee, R. A., Perelman, D. S., Lee, S. L. and Keer, L. M. (1968). "Seismic Response of Structure-Foundation Systems," J. Eng. Mech. Division, Vol.94 (EM6): 1295-1315.

[8] Horikoshi, K. and Randolph, M. F. (1998). “A contribution to optimum design of piled rafts,” Geotechnique, Vol.48(3): 301-17.

[9] Mazzoni, S., Mckenna, F., Scott, M. H., Gregory, L. and Fenvas. (2007). "OpenSees, Open System for Earthquake Engineering Simulation User command- Language manual,”Available online: http://opensees.berkeley.edu.

[10] Roy, R. and Dutta, S.C. (2010).“Inelastic Seismic Demand of Low-rise buildings with Soil flexibility,” Int. J. Nonlinear Mech., Vol. 45: 419-432.

[11] Velez, A., Gazetas, G. and Krishnan, R. (1982). "Lateral dynamic response of constrained head piles," J. Geotechnical \& Geoenv. Engrg., Vol. 109(8): 1063-1081.

[12] Boulanger, R.W., Curras, C. J., Kutter, B. L., Wilson, W. D. and Abghari, A. A. (1999). "Seismic soil-pile-structure interaction experiments and analyses," J. Geotechnical \& Geoenv. Engrg., Vol. 125(9): 750-59.

[13] Curras, J. C., Boulanger, W. R., Kutter, B. L. and Wilson, D.W. (2001). "Dynamic Experiments and Analysis of a Pile-Group-Supported Structure", J. Geotechnical \& Geoenv. Engrg.,Vol.127(7): 585-596. 